\title{
Is Anyone Out There?
}

In the shadows of the struggles surrounding the construction of the 140 Foot Radio Telescope, Frank Drake, NRAO's newest and youngest scientist, carried out a small observing project to detect radio signals from nearby stars that would indicate the present of extraterrestrial intelligent life. Naming his program "Project Ozma," after the mythical princess of the Land of Oz, Drake observed two nearby stars, Tau Ceti and Epsilon Eridani. This project, the first modern Search for Extraterrestrial Intelligence (SETI), captured the imagination of the public and scientific communities alike. In the following decades, other investigators initiated a variety of SETI programs of ever-increasing capability at NRAO and elsewhere. NASA began a major SETI program, but it became mired in controversy over whether searching for intelligent life in the Universe is a proper scientific pursuit or should be relegated to the realm of science fiction. While no confirmable evidence for extraterrestrial intelligent life has yet been found, the discovery of the widespread existence of other planetary systems combined with the vastly improved sensitivity of radio telescopes has reinvigorated SETI research, and the exciting promise of detection continues to attract the attention of new generations of astronomers and the public.

\subsection{Project Ozma}

Frank Drake had long been fascinated by the possibility of life on other worlds and more generally by science and engineering. On a Navy ROTC ${ }^{1}$ scholarship, he followed these interests by enrolling at Cornell University. Initially

The title of this chapter is taken from the book by Frank Drake and Dava Sobel 1992, Is Anyone Out There? The Scientific Search for Extraterrestrial Intelligence (New York, NY: Delacorte Press). 
interested in designing airplanes, Drake ultimately settled on a degree in engineering physics. Cornell also provided the opportunity for Drake's first forays into astronomy. He enrolled in an elementary astronomy course and was captivated by the lectures of Otto Struve, and he even built a small optical telescope. Although Drake wanted to pursue his interests in astronomy by enrolling in a graduate astronomy program, he first had to complete his required Naval service.

During his three years of active duty, Drake was a Naval electronics officer, learning skills that would soon greatly impact his future career. After his time in the Navy, he enrolled in 1955 in the graduate astronomy program at Harvard University. Bart Bok, chair of the Harvard astronomy program, quickly put Drake's electronics training to work by offering him a position with the Harvard radio astronomy project, where he further developed his technical abilities and became a skilled radio astronomer. After receiving his $\mathrm{PhD}$ from Harvard based on studies of neutral hydrogen in galactic clusters, Drake joined the NRAO. He arrived in Green Bank in April 1958, joining Dave Heeschen and John Findlay as the only other members of the scientific staff ${ }^{2}$ (Fig. 5.1).

As described in Chap. 4, within a few months of Drake's arrival in Green Bank, NRAO acquired an 85 foot radio telescope. The new 85 foot Tatel Radio Telescope was essentially off the shelf, and did not have the collecting area or precision of the planned 140 Foot Radio Telescope. However, Drake realized that an 85 foot antenna had the capability to detect radio signals equivalent to Earth's most powerful transmissions from a distance of up to 10 to 20 light-years. Carefully choosing the right occasion, Drake softly suggested the first SETI project over lunch one day with Heeschen, Findlay, and Acting NRAO Director Lloyd Berkner. Drake proposed using the Tatel Telescope to search for signs of extraterrestrial life from nearby stars. To Drake's surprise and

Fig. 5.1 Frank Drake, 1962. Credit: NRAO/ AUI/NSF

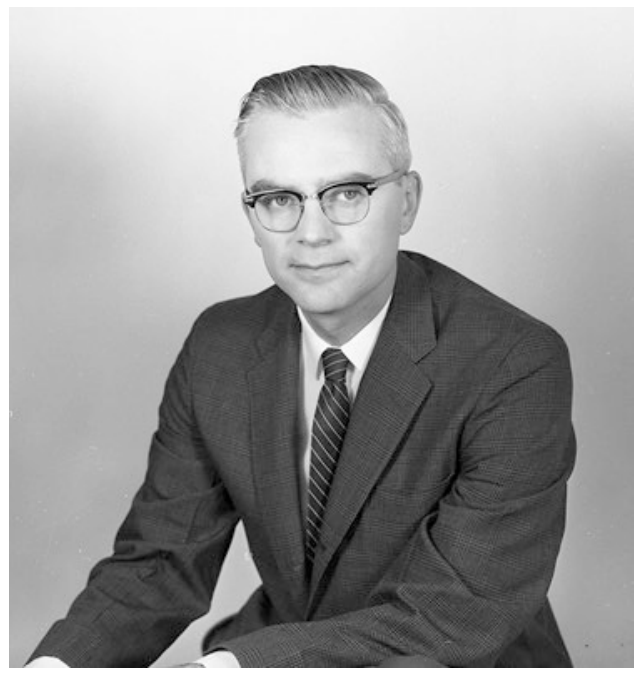


delight, Berkner, whom Drake described as being an optimistic gambler in science, immediately gave his enthusiastic approval and encouragement. Drake dubbed his investigation Project Ozma after the fictional princess Ozma of the Land of $\mathrm{Oz}$ in L. Frank Baum's series of Oz books, suggesting a sense of "a land far away, difficult to reach, and populated by strange and exotic beings" (Drake and Sobel 1992). Project Ozma thus became the first modern Search for Extraterrestrial Intelligence $(\mathrm{SETI})^{3}$ and the standard by which future search programs have been measured.

Drake selected two nearby Sun-like stars, Tau Ceti and Epsilon Eridani, for his search. T. Kochu Menon, a fellow radio astronomy graduate from Harvard, had recently joined the NRAO scientific staff and was interested in studying magnetic fields in galactic hydrogen clouds using what is known as the Zeeman effect. ${ }^{4}$ The instrumental requirements to search for the Zeeman effect were similar to those Drake would need for Project Ozma, and Menon and Drake went to work together to build the equipment needed for their projects, with the Zeeman experiment serving as a convenient front for Ozma (Fig. 5.2).

On 11 April 1960 Drake made the first observations for Project Ozma (Fig. 5.3). After six hours of observing Tau Ceti with no results, he turned the antenna toward Epsilon Eridani, the third closest star to the Sun located only about 10 light-years away. ${ }^{5}$ Almost immediately Drake saw an off the scale

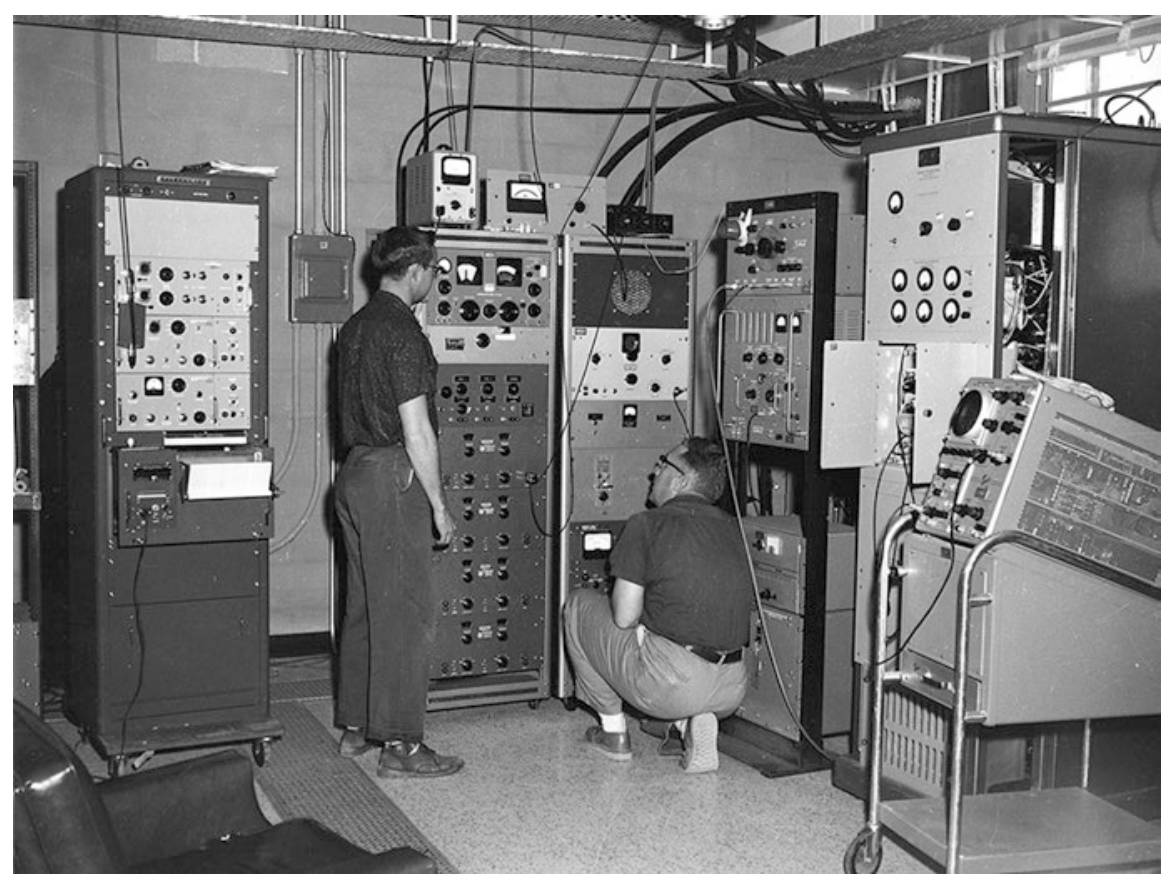

Fig. 5.2 Tatel Telescope control room used during Drake's 1960 Project Ozma. Credit: NRAO/AUI/NSF 


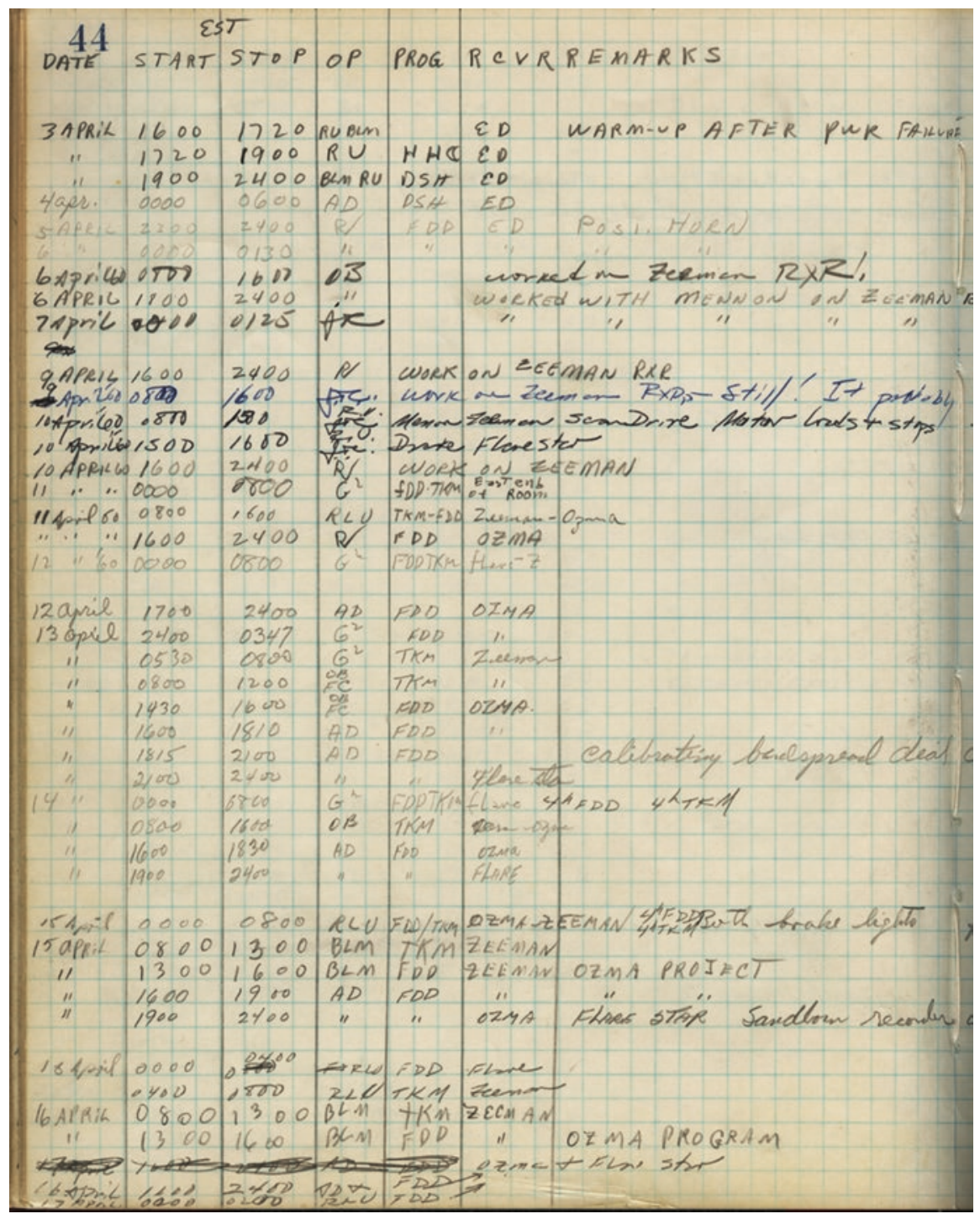

Fig. 5.3 Tatel Telescope log book for April 1960, with entries for Ozma observations on 11-16 April. Credit: NRAO/AUI/NSF

pulsed signal-8 pulses per second. An apparent successful detection of signals from another planet stunned Drake and his colleagues. Drake later recalled his experience, "When it happened, we were all dumbfounded. Could it be this easy? All you need to do is point to a random star and within a minute you see a signal that puts a receiver into overload? We were so surprised and so unprepared for it, we didn't know what to do. Everybody just looked at each other." ${ }^{\prime \prime}$ 
But detecting signals from extraterrestrial intelligence was not to be that easy. The signal lasted for only a few minutes and Drake spent the next few days trying to confirm the apparent detection. To determine whether the signal was of terrestrial or extraterrestrial origin, he placed a small horn antenna, which was sensitive to radiation coming from a wide area of sky, outside the control building window. About ten days later they again saw the same signal. But both the Tatel Telescope and the horn antenna detected the signal with equal intensity, and it was clear that it originated from a terrestrial source, but one of unknown origin. Twenty-five years later at a gathering of the group involved in the original Ozma study, Drake commented, "We have never known what that was, but it had all the earmarks of being an electronics countermeasure system, probably airborne based on the timescale during which we heard it." (Kellermann and Seielstad 1986, p. 25).

After a little over a week of observing, there was a catastrophic receiver failure. Drake took a short break to get the receiver fixed while the telescope was used at another frequency for more conventional radio astronomy observations. When Drake resumed his observations, he continued to observe both Tau Ceti and Epsilon Eridani. But after 150 hours of observing spread over a total period of about two months between April until late June, there were no suggestions of any signals from either Tau Ceti or Epsilon Eridani.

The amount of data collected for Project Ozma motivated NRAO to implement new, digital methods of recording data. Initially all data for Project Ozma was recorded with a moving pen on strip charts, the standard technique for recording radio astronomy data at the time. However, Drake and his colleagues soon found that analyzing these chart recording was extremely tedious, and over the course of the project they developed the first digital data-recording system used at NRAO. At first they used a newly available digital voltmeter with a nixie tube display. This setup required the observer to press a button to freeze the display and then write down the numerical output of the receiver. Later, they attached a printer to the digital output to avoid the tedious task of writing down the numbers. Drake recalled the next leap forward in the process:

The dramatic breakthrough that took place then was that [visiting] astronomer Gart Westerhout came and recognized that he could make life much more pleasant for himself if he attached a string to the button so that he wouldn't have to stand by the button. He rigged a string across the ceiling of the telescope control room and down from the ceiling right over an easy chair, in which he could sit. He attached a pull[ey] to this string and then he sat in the easy chair and whenever he wanted to take a reading he would pull the chain. (Kellermann and Seielstad 1986, p. 24)

Ultimately the system evolved to record the digital output of the receiver on punched paper tape to be analyzed later by NRAO's first computer, an IBM 610 . 


\subsection{Cocconi And Morrison Paper}

Concerned that the scientific community would view Project Ozma as science fiction and a waste of resources, Drake and newly appointed NRAO Director Otto Struve initially agreed not to publicize it. The fledging Observatory was already facing extensive criticism resulting from what many felt were the heavyhanded methods used by AUI in securing the NSF contract to operate NRAO, the delays and cost overruns of the 140 Foot construction, and envy over the generous way the Observatory was being funded compared to the university astronomy facilities. However, their hand was forced when Cornell physicists Giuseppe Cocconi and Philip Morrison published their September 1959 Nature paper, "Searching for Interstellar Communication" (Cocconi and Morrison 1959). Drake was pleased that his ideas had been independently discussed by two prominent scientists, in particular Morrison, who had earlier played a major role in the Manhattan Project at Los Alamos and who had personally assembled the atomic bomb dropped on Hiroshima. However, Struve was annoyed that Drake and NRAO were not receiving credit for their enterprising plans. It was Frank Drake who not only was the first to suggest searching for $21 \mathrm{~cm}$ radio signals from extraterrestrial intelligence, but who also took the initiative to build the necessary instrumentation, and planned to carry out the first meaningful search.

Despite that, Cocconi and Morrison were receiving all the attention from both scientists and the public. Struve and Drake wanted to ensure that NRAO would get the proper credit for their pioneering work. So in November 1959, reacting to the Cocconi and Morrison paper, Struve announced the existence of Project Ozma in his Karl Taylor Compton Lectures in Astronomy at MIT where he said ${ }^{7}$ :

Many of us have seen a report that thus far has come only in a mimeographed form from 2 American Scientists now in Europe. I believe their paper is soon to be in Nature. At Green Bank we are also thinking about this problem and there is underway a project which goes by the letters O-Z-M-A and I do not recall what these letters stand for, but those of us who forget what the name means, call it the project of the little green men. ${ }^{8}$

Curiously, in the published version of his lectures, written more than a year later, Struve (1962) made no mention of Project Ozma. Also, four months before his Project Ozma began, Drake discussed the problem of detecting transmissions from distant planetary systems in a January 1960 popular article in Sky and Telescope where he also described his plans for Project Ozma (Drake 1960). Both Drake and Struve were treading a fine line. They did not want NRAO to be ridiculed for spending money on what might be perceived as a science fiction project; but neither did they want to be scooped by others. So Drake wrote to the NSF Press Officer with an "On Demand Information Regarding NRAO Project Ozma" press release describing Project Ozma and 
saying, "We very much wish to withhold this information from the press until such time as the experiment is successful" and "if the press should become aware of the project ... or if another group also embarks on research in this field." "Nevertheless, as a result of Drake's article, Struve's lectures, and the Cocconi and Morrison paper, the search for extraterrestrial civilizations drew increased interest from both the scientific community and the public. ${ }^{10}$

Cocconi and Morrison had considered what type of signal extraterrestrial civilizations might use in an attempt to contact each other or to announce their existence. They argued that since hydrogen was the most abundant element in the Universe, a fact which would be known to any intelligent being, the best place to start searching for signals from extraterrestrial life would be the $1420.405 \mathrm{MHz}(21 \mathrm{~cm})$ radio line of neutral hydrogen. Curiously, Drake chose this same frequency for Project Ozma, but not for the same reasons as Cocconi and Morrison. By selecting the $21 \mathrm{~cm}$ line, Drake could then bury the \$2000 development costs as part of Menon's project to detect the Zeeman effect (Drake and Sobel 1992, p. 28). Recalling the planning process for Project Ozma, Drake later explained, "We would build it and do the search at the 21 centimeter line.... It was a way to prevent criticism of the Observatory, and in a way, kill two birds with one stone." (Kellermann and Seielstad 1986, p. 19). Drake's plan for Project Ozma thus allowed him to meet his scientific goals for the project while limiting the criticism that could be leveled against NRAO.

As a result of the reluctantly released publicity, Microwave Associates gave Drake one of the first parametric amplifiers used in radio astronomy, which allowed a major improvement in sensitivity not only for Project Ozma, but for Menon's Zeeman experiment, as well as other $21 \mathrm{~cm}$ projects on the Tatel Telescope. Interestingly, with time some SETI researchers pointed out that $1420 \mathrm{MHz}$ is the wrong place to search, since any intelligent civilization would want to keep that frequency quiet for radio astronomers. ${ }^{11}$ Later SETI researchers focused on the region between the $21 \mathrm{~cm}$ hydrogen line and the $18 \mathrm{~cm}$ hydroxyl $(\mathrm{OH})$ line which has been characterized as the "water $\left(\mathrm{H}_{2} \mathrm{O}\right)^{12}$ hole," an equally logical place for a water based civilization to transmit their presence (e.g., Oliver 1979).

\subsection{Reactions to SeArching for Extraterrestrials}

Cocconi, Morrison, and Drake all anticipated that their speculations would meet criticism from other scientists due to the widespread perception that extraterrestrial life was more of a plot device for science fiction novels than a serious topic of scientific discussion. Indeed, the Cocconi and Morrison paper created quite a stir in both the scientific and popular press. Their primarily theoretical paper resulted from follow-up discussions of a paper Morrison had published the previous year on gamma ray astronomy. In their discussions, Cocconi and Morrison realized that gamma rays were being artificially produced at Cornell, just a few floors below them as a by-product of the university's synchrotron experiments. They structured their paper in a way to limit 
criticism they expected to receive. By assuming that intelligent, communicative life existed on other planets, they concentrated on the best methods for attempted contact and their article focused on this issue. "We shall assume that they (an extraterrestrial civilization) established a channel of communication that would one day become known to us... What sort of channel would it be?" Though their initial discussions addressed artificially produced gamma rays, based on energy considerations and relative transparency of the interstellar medium and planetary atmospheres, they concluded that radio frequencies between $1 \mathrm{MHz}$ and $30 \mathrm{GHz}$ provided the best opportunity for establishing interstellar communication. Furthermore, they noted that an advanced alien civilization would use the most obvious and simplest wavelength to communicate with our relatively primitive civilization, and that would be the $21 \mathrm{~cm}$ $(1420 \mathrm{MHz})$ line of neutral hydrogen, the most abundant element in the Universe. In their Nature paper, Cocconi and Morrison concluded, "We therefore feel that a discriminating search for signals deserves a considerable effort. The probability of success is difficult to estimate; but if we never search, the chance of success is zero."

In common with all subsequent SETI programs to date, Project Ozma found no evidence for any intelligent extraterrestrial civilizations, although some skeptics questioned whether there was intelligent life on Earth, or at least in Green Bank.

But Project Ozma did not go unnoticed. During this period, Green Bank was visited by West Virginia Governor Cecil Underwood, by Theodore Hesburgh, the new president of the University of Notre Dame, and by Bernard Oliver, the vice president of Hewlett Packard, who would later play a major role in the American program to detect radio signals from an extraterrestrial civilization. Representatives of various news media also visited Green Bank, and Drake was interviewed for television, complete with cue cards.

All NRAO telescopes were actually controlled by a professional telescope operator based on instructions from the scientist in charge of the program. During Governor Underwood's visit, the telescope operator noted the Governor's visit in the logbook by writing in parenthesis, "Republican fool." On another occasion, a newscaster quietly took the telescope operator aside to ask, "If you had really heard something, you would tell me; wouldn't you?" (Crews 1986, p. 29). But after examining hundreds of yards of chart paper, Project Ozma disclosed nothing but noise (Drake 1979, p. 13). While Ozma was not successful in the narrow sense of detecting extraterrestrial civilizations, in a broader sense Ozma brought SETI to the public arena and defined all subsequent work in the quest for extraterrestrial civilizations. Drake never expanded Project Ozma to look at other stars, but over the next half century he became the recognized senior statesman and spokesman for SETI. No doubt his growing stature was enhanced by his prematurely white hair, which conveyed an image of wisdom and authority even when he was a young Green Bank astronomer. 
With no positive results to report, Drake never published the results of Ozma in the refereed scientific literature. However, in a 1961 paper in Physics Today, Drake discussed the arguments for searching for advanced extraterrestrial civilizations and gave a technical description of the Ozma instrumentation. In a very brief statement, he simply said, "A search for intelligent transmissions has been conducted in Green Bank. We looked at two stars, Tau Ceti and Epsilon Eridani, which are the nearest solar system type stars. After some 150 hours of observing, we obtained no evidence for strong signals from these stars." (Drake 1961).

In their paper, Cocconi and Morrison discussed the broader issue of whether searching for extraterrestrial intelligence should be considered a legitimate scientific activity and noted, "The reader may seek to consign these speculations wholly to the domain of science-fiction." However, Cocconi and Morrison argued that the search for extraterrestrial intelligence lay on firm theoretical grounds and should be considered a valid scientific inquiry and went on to say, "We submit, rather, that the presence of interstellar signals is entirely consistent with all we now know, and that if the signals are present the means of detecting them is now at hand."

Recalling the public reaction, Morrison (1990, p. 24) said in a later interview, "It got huge newspaper and media coverage, which we didn't anticipate... The media kept chasing me because I was going around the world. In every city I visited there would be messages from reporters wanting to talk to me..." The attention SETI received in the public media can be attributed to the booming interest in extraterrestrial life and the growing enthusiasm for space exploration. Project Ozma was no doubt connected in the public's mind with the widespread fascination with "flying saucers" that had developed following the Roswell $\mathrm{UFO}^{13}$ incident a decade earlier and with the popular speculation that UFOs or flying saucers were spacecraft sent to Earth by aliens from another planet. But the nature of this attention was a double-edged sword. Increased general interest in SETI would be a key factor in receiving funding for future SETI projects; however, SETI scientists also wanted to ensure that their work was viewed as valid scientific research, not lumped together with UFO sightings.

Indeed, while the reaction of the public was generally positive, the scientific community had more mixed views. Drake recalled the attitude of his colleagues as, “...uniformly positive but not enthusiastic. Again I think that it was the fact that we weren't investing a great deal of resources... People didn't think it was worth a very careful analysis, but since it wasn't crazy they said: These guys want to spend two thousand dollars, let them do it." (Drake 1990, p. 69). Morrison's recollection of his colleagues' reactions echoed Drake's experience, "Most felt it was not a good idea, probably foolish, certainly completely speculative, and hardly worth discussing." (Morrison 1990, p. 24). Though reactions were mixed in the scientific community, the attention that Cocconi, Morrison, and Drake received helped to connect scientists who were interested 
in extraterrestrial intelligence. Drake later commented that finally, "People knew who they could write to find out who was interested" (Drake 1990, p. 60).

\subsection{Development of the SETI Community}

After his earlier hesitation, Drake did not shy away from public exposure. Encouraged by the increasing interest, if not support for SETI, Drake thought about holding a conference to discuss Project Ozma and the broader aspects of extraterrestrial life, in particular intelligent civilizations. Following a talk Drake gave at the Philosophical Society of Washington on the "Detection of Extraterrestrial Intelligent Life," he exchanged ideas with Peter Pearman, a staff officer of the National Academy of Science's (NAS) Space Studies Board (SSB). ${ }^{14}$ After returning to Green Bank, and with the concurrence of Struve, Drake proposed a "quiet symposium on extraterrestrial life" to be held in Green Bank which the SSB agreed to sponsor with NRAO acting as the host. ${ }^{15}$ Pearman defined the goals of the meeting as. ${ }^{16}$

a) The considerations which may lead to the expectation that intelligent transmitters are likely to be observable;

b) Whether or not it would be worthwhile to engage in further exploratory investigations with existing apparatus or whether the prospects of detecting an interesting event are, in fact, too small to be of interest;

c) If the consensus turns out to be largely negative, it may be that some suggestions can be derived for further investigations which could be made either to verify or to refute the null hypothesis or which might enable a re-assessment to be made.

According to Drake, Pearman was trying to build support in the government for the possibility of discovering life on other worlds (Drake 2010). It did not hurt that Lloyd Berkner, President of AUI, was the Chair of the SSB, although curiously, Berkner did not attend the Green Bank conference. Participation in the Green Bank conference was by invitation only and Struve requested that the invitees cooperate in conducting the conference "privately, without publicity or press coverage." 17 This became only the second scientific conference held in Green Bank, following the joint US-USSR radio astronomy meeting held six months earlier.

Held on 1-2 November 1961, the Green Bank Conference on Extraterrestrial Intelligent Life brought together a diverse group of scientists and engineers to discuss issues pertinent to communicative extraterrestrial life. Participants included Morrison and Cocconi; Su-Shu Huang, author of papers on planet formation; John C. Lilly, author of the book Man and Dolphin on dolphin intelligence; and chemist Melvin Calvin, who was notified during the conference that he had received the 1961 Nobel Prize in Chemistry, giving a celebratory atmosphere to the gathering. Carl Sagan and Bernard Oliver also attended, 
both of whom would later play key roles in future SETI activities. NRAO Director Otto Struve acted as Chair.

The Green Bank conference provided the opportunity to examine the assumptions Drake, Cocconi, and Morrison had previously made about extraterrestrial intelligent life. As previously discussed, these first publications were limited to technical issues in order to limit the criticism their projects would encounter. However, at the Green Bank conference the attendees expanded their analysis to include debating the possibility of the existence of extraterrestrial life based on current understanding of astronomy, planet formation, and evolution, the optimum frequencies for communication, the form of messages, and, even at this early stage, they speculated on when it would be appropriate to send our own messages.

In preparation for the conference Drake organized his thoughts into a format that would shape subsequent SETI investigations for the next half century. The Drake Equation estimated the number of communicative civilization in the Galaxy by accounting for factors necessary for intelligent life to develop. This included the number of stars with habitable planets in the Galaxy, the fraction of those planets that develop life, and most important, but also most uncertain, the mean lifetime of a technical, communicative civilization.

The Drake Equation is given by:

$$
N=R_{*} f_{p} n_{e} f_{l} f_{i} f_{c} L
$$

where

$R_{*}=$ mean rate of star formation over galactic history

$f_{p}=$ fraction of stars with planetary systems

$n_{e}=$ number of planets per planetary system with conditions ecologically suitable for the origin and evolution of life

$f_{l}=$ fraction of suitable planets on which life originates and evolves to more complex forms

$f_{i}=$ fraction of life-bearing planets with intelligence possessed of manipulative capabilities

$f_{c}=$ fraction of planets with intelligence that develops a technological phase during which there is the capability for and interest in interstellar communication

$L=$ mean lifetime of a technological civilization

Throughout history humanity has often speculated on the possibility of extraterrestrial civilizations. In the early part of the twentieth century, there were even primitive attempts to make contact with Martians or civilizations elsewhere in the Galaxy ${ }^{18}$ (See Dick 1993, 1998). But for the first time, the Drake equation put these speculations on a quantitative basis. Although none of the factors in the Drake equation could be reliably estimated at the time, the 
conference participants could optimistically argue that each of the first six factors could be in the range of 0.1 to 1 . The big uncertainty was the lifetime of technically advanced civilizations, which might be as short as a few hundred years or as long as hundreds of millions of years for those civilizations that did not destroy themselves by war or by exhausting their resources. ${ }^{19}$ Subsequent work leading to the recognition of the widespread existence of exoplanets and advances in evolutionary biology has mostly confirmed these early speculations, leaving $L$ as the big uncertainty.

The camaraderie of Green Bank conference attendees was evident at the meeting as they dubbed themselves the Order of the Dolphin, and Calvin had dolphin pins made in honor of Lilly. The formation of the Order of the Dolphin demonstrated the sense of group identity that developed during the conference. Although the Order never developed into an official organization in any sense, after the meeting Carl Sagan wrote to J.B.S. Haldane inviting him to join the Order. Haldane's response to Sagan's request illustrates the type of organization the Order of the Dolphin was. Sagan recalled his response, "...he (Haldane) wrote me that membership in an organization that had no dues, no meetings, no responsibilities was the sort of organization he appreciated; he promised to try hard to live up to the duties of membership." (Sagan 1973, p. 168). For the next few decades, the Green Bank conference attendees formed the core group of scientists involved in the search for extraterrestrial intelligence.

Following the 1961 Green Bank meeting, many of the still surviving participants returned to Green Bank in 1985 to celebrate the 25th anniversary of Project Ozma (Kellermann and Seielstad 1986) (Fig. 5.4). But at the 2010 50th anniversary workshop, only Frank Drake himself was able to participate. ${ }^{20}$ By the time of the 1985 conference, the search for extraterrestrial civilizations had split between two strategies. One approach was to look for extraterrestrial beacons consisting of high-powered transmitters and highly directional antennas that might be pointed toward the Earth. However, beacon research assumes that the extraterrestrial civilization has some knowledge of the Earth as being inhabited by a technical society. The other approach is to look for signals resulting from the analogue of Earth's entertainment broadcasting or the powerful defense related radars-so-called "eavesdropping." The 1985 conference participants vigorously debated the relative merits of the two approaches, as well as the effectiveness of looking outside the radio band, in particular at optical or infrared wavelengths, where Harvard's Paul Horowitz was beginning an innovative search.

Unlike most previous SETI conferences, the 2010 Green Bank 50th workshop paid less attention to technical and implementation strategies, instead discussing such things as the social, moral, religious, and legal implications of a confirmed discovery of an extraterrestrial civilization, and the likely societal reactions. The participants also reflected on the accomplishments and impact of the previous half century of SETI and speculated on the possible consequences 


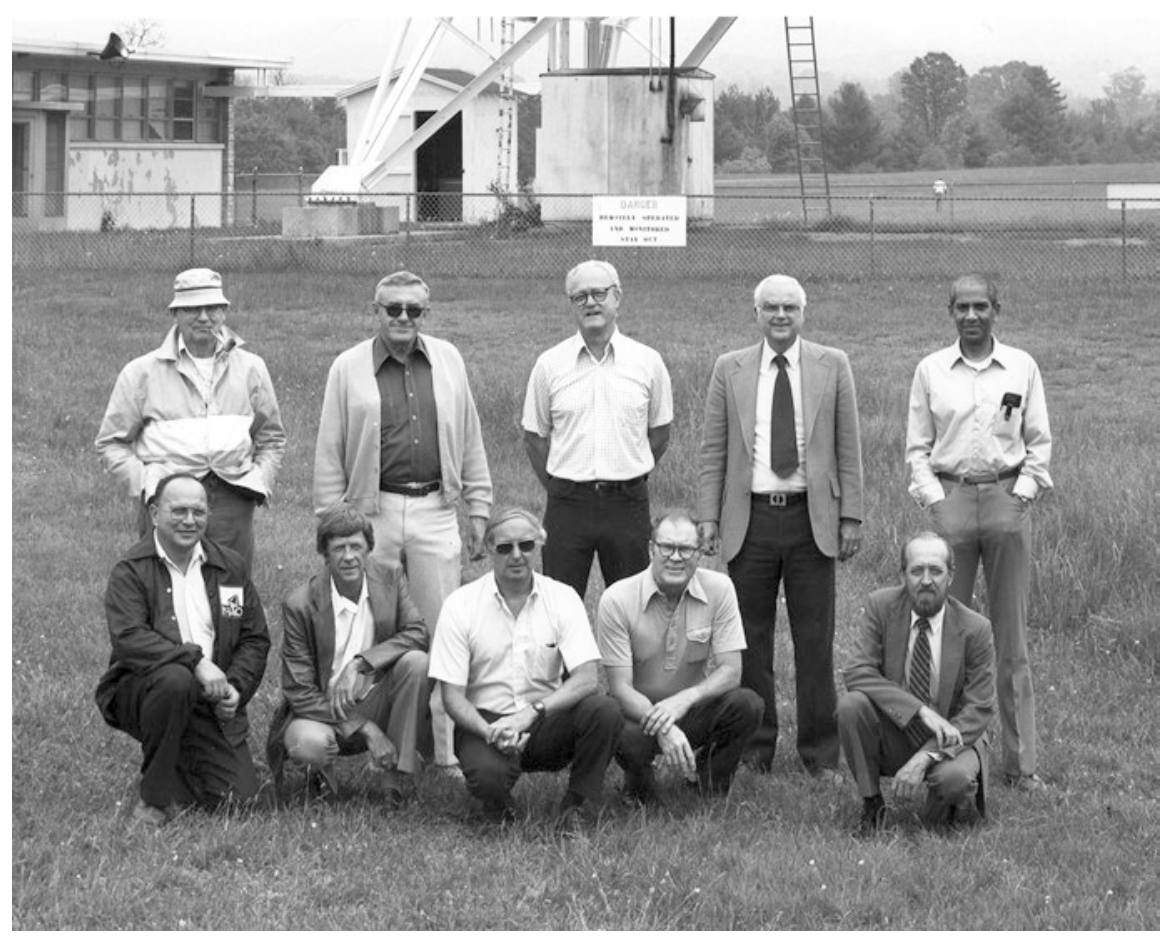

Fig. 5.4 25th Project Ozma reunion, Green Bank, 1985. Front (left to right): Bob Viers, Dewey Ross, Bill Meredith, Troy Henderson, Bob Uphoff. Back: George Grove, Fred Crews, Omar Bowyer, Frank Drake, Kochu Menon. Credit: NRAO/AUI/NSF

of realizing that we may be alone in the Universe. Among the participants of the 2010 workshop was Judge David Tatel, the son of Howard Tatel who had designed the 85 foot Green Bank telescope for the Blaw-Knox Company when he was working at the Carnegie Institution's Department of Terrestrial Magnetism. His son, David, a distinguished jurist and member of the US Court of Appeals for the District of Columbia Circuit, shared his thoughts on the legal and moral implications of a confirmed detection of a transmission from an extraterrestrial civilization.

For years after Drake's short-lived observations, Project Ozma became one of the most highly discussed programs at NRAO and the focus of broader discussions about NRAO. Ozma, along with Cocconi and Morrison's famous paper and the 1961 SETI Conference, launched SETI into the popular vernacular (Drake and Sobel 1992). Criticism of SETI often focused on the whimsical nature of searching for signals from extraterrestrials and was often discussed in the same way as the widely debunked UFO research. Scientists such as Drake, Morrison, and Sagan, argued against that characterization of their work, claiming that the advent of the modern radio telescope provided the 
technology to conduct a sober, scientific search for interstellar signals of intelligent origin.

\subsection{Seti After Project Ozma}

In 1963, Drake left NRAO for the Jet Propulsion Laboratory (JPL) in Pasadena, California. Frustrated by the bureaucracy and paperwork associated with a NASA laboratory, he left JPL to become Director of the Cornell Arecibo Observatory after only a year. There he initiated a number of SETI programs, often in collaboration with Carl Sagan. ${ }^{21}$ In the years following Project Ozma, NRAO accepted proposals to use the 300 Foot and 140 Foot Radio Telescopes in competition with other proposals for more conventional astronomical research, but only if the investigators agreed to publish in the normal literature and not solicit undue publicity. Gerrit Verschuur used the 140 Foot and 300 Foot Telescopes to search for intelligent signals from possible planets orbiting ten nearby stars (Verschuur 1973), but buried his SETI observations as part of a more extensive program to study galactic neutral hydrogen clouds. Only about a decade after Ozma, Verschuur estimated that his search was already about 30 times more sensitive than Drake's Ozma. Radio astronomers Pat Palmer and Ben Zuckerman convinced NRAO to spend 500 hours to observe 674 stars with the 300 Foot antenna which they dubbed Project Ozma II or Ozpa. But perhaps concerned that if they tried to publish in a peer reviewed astronomy journal they might damage their reputation as rapidly rising young radio astronomy stars, they reported their work first in an internal NRAO newsletter (Palmer and Zuckerman 1972) and later in the proceedings of a 1979 IAU conference (Zuckerman and Tarter 1980).

In 1974, Frank Drake again shook the scientific community with a dramatic and bold experiment. As part of the ceremonies marking the inauguration of the Arecibo radio telescope upgrade, Drake used Arecibo's powerful millionwatt transmitter to broadcast a message to the globular cluster M13 located about 21,000 light years away. Drake's message consisted of a stream of 1679 bits of 1's and 0's which, he argued, any intelligent species would recognize as the product of the prime numbers 73 and 23 . When arranged in a pattern of 73 lines by 23 rows, the 1's and 0's conveyed a simple picture of human life.

Until Drake's Arecibo message, all previous SETI research was passive. That is, powerful radio telescopes were used to try to receive transmissions originating from extraterrestrial civilizations. Drake reasoned that if everyone only listened, there would be no signals to receive. At a distance of 21,000 light years, it would be at least 42,000 years before one might expect a reply from M13. Nevertheless, Drake's message generated some controversy. In England, Martin Ryle argued that by sending a message, Drake was irresponsibly disclosing our presence to any alien civilization that might live on a planet orbiting a star in Ml3, and that there was no guarantee that such a civilization would be friendly. Of course, since the 1920s humans had begun broadcasting radio signals into space. And starting in the 1950s with the rise of powerful TV trans- 
mitters and the Distant Early Warning system (the DEW Line) radar, manmade radio signals from the Earth were already propagating through the Galaxy and could be detected by alien civilizations no more advanced than our own. In fact, due to these artificial radio transmissions at VHF and UHF frequencies, to a distant observer the Earth appears brighter than the natural radio emission from the Sun.

The increasing number of SETI programs, particularly in the United States, perhaps fueled by Drake's transmission to $\mathrm{Ml} 3$, raised numerous ethical, moral, legal, and political questions about how to react to the reception of any signal thought to come from an advanced extraterrestrial civilization. Should a successful detection be kept confidential or immediately made public, and if made public should national governments be consulted first? If consulted, would governments try to classify any relevant information about the detection? If made public how would countries (particularly rogue countries), religious or quasi-government groups, or even individuals be constrained from responding and perhaps misrepresenting our society and culture? Behind much of the debate is the uncertainty about whether alien civilizations would be benevolent or would be a threat, intentional or not, to emerging societies, and it was noted that the history of contact between terrestrial civilizations is not encouraging in this respect. ${ }^{22}$

It was becoming increasingly clear not only to scientists, but to the public and particularly politicians, that the detection of signals sent by extraterrestrials or aliens would have a profound impact on human life. At worst, it was feared that two-way contact with aggressive aliens with advanced weaponry might destroy our civilization, much as the colonial powers on Earth have destroyed the less technologically developed earthly societies with which they came into contact. At the other extreme was the possibility of obtaining advanced medical knowledge with the promise of curing famine and disease, and providing advanced technologies to support human activities as well as the immeasurable impact to human religious beliefs. SETI was becoming too important for the government to leave to scientists.

At the request of Don Fuqua, Chairman of the US House of Representatives Subcommittee on Space Science and Applications, ${ }^{23}$ the Library of Congress Science Policy Research Division ${ }^{24}$ issued a report on the "Possibility of Intelligent Life Elsewhere in the Universe." The report, which was compiled by Science and Technology Analyst Marcia Smith (Smith 1975), gave a definitive update on the status of SETI research in both the United States and the USSR. It served to legitimize SETI and served as a blueprint for future SETI programs. In 1982, the International Astronomical Union set up a new commission on "Bioastronomy: Search for Extraterrestrial Life." Further legitimization of SETI came from the 1980, 1991 and 2001 National Academy of Sciences Decade Reviews of astronomy which recognized the Search for Extraterrestrial Intelligence as an important and valid area of scientific research, and the special role played in SETI by radio astronomy (Field 1982, p. 150-151; Bahcall 1991a, p. 62; McKee and Taylor 2001, p. 131-132). Perhaps an even more influential endorsement came from Theodore Hesburgh, President of 
Notre Dame, who wrote, "This proposed search for extraterrestrial intelligence (SETI) is also a search of knowing and understanding God." (Morrison et al. 1977, p. vii).

In view of the large uncertainty in the nature of the signals being sought, the National Academy reports stressed the need for a variety of approaches by independent researchers, and cautioned against too much reliance on highly organized and visible agency-directed expensive programs such as those being pursued by NASA. The NASA SETI observations began in the early 1970 s when Jill Tarter, Jeff Cuzzi, and others used the Green Bank 300 Foot Radio Telescope to search for narrow band radio signals. ${ }^{25}$ But by this time, it had become apparent that no existing or planned radio telescope probably had sufficient sensitivity to detect signals from any but the nearest stars. Under the leadership of Bernard Oliver, NASA convened a summer study to design a radio telescope with at least two orders of magnitude better sensitivity than any existing facility that would be capable of a meaningful SETI search (Oliver and Billingham 1973). Project Cyclops, as it was known, was to consist of an array of more than one thousand 100-meter antennas. The study team also identified a number of exciting radio astronomy applications, but the anticipated cost of approximately $\$ 10$ billion far exceeded any conceivable funding. ${ }^{26}$ Nevertheless, Oliver's bold vision served to ignite the scientific community, especially radio astronomers, to the prospects for SETI investigations, as well as to begin to smooth the way toward the construction in the US of a large multiple antenna array for more conventional radio astronomy programs. But the Cyclops study also had a negative impact. Although never intended to be a blueprint for an actual construction program, the high price tag left a long-lasting stigma that the search for extraterrestrial civilizations involved huge amounts of money that could be better spent, depending on one's outlook, on conventional astronomy or on addressing the nation's sociological problems.

SETI and NASA NASA's involvement in Project Cyclops led to a series of workshops organized by John Billingham at the NASA Ames Research Center. Billingham, who was a British military medical doctor and head of a small group called the Committee on Interstellar Communications within the Exobiology Office at Ames, had previously recruited Bernard Oliver to lead the Cyclops study. He was probably the first person to be head of a US government office with official responsibility for extraterrestrial intelligence (Billingham 1990). Billingham's committee was part of the NASA Life Science Division which was the result of NASA's interest in life beyond the Earth. The NASA SETI workshops, which were chaired by Morrison, were convened to systematically examine the fundamental basis of SETI, the preferred search approaches, and the social, environmental, and political impact of the success or failure of SETI. They concluded that SETI was timely and feasible, that a significant program would not require substantial resources, and that the US could take the lead in this intrinsically international endeavor. 
The report of the NASA workshop on "The Search for Extraterrestrial Intelligence" (Morrison et al. 1977) laid out the blueprint for the American SETI program for the following decades, and by the close of the 1970s, SETI had developed a robust community of scientists and engineers, strong public support, and sets of detailed options for future work. Interestingly, although there has been no space based component of the US SETI program, starting with the Ames workshops, for several decades the US SETI effort was led by NASA rather than by the NSF which, at the time, had no interest in life beyond the Earth.

The end of the 1970s brought strong challenges to further SETI research in the United States. In February 1978, Senator William Proxmire (Wisconsin) awarded SETI his infamous "Golden Fleece Award," a dubious monthly honor meant to single out projects that the Senator felt wasted federal funds. In making his announcement of the "award," Proxmire suggested that NASA was "riding the wave of popular enthusiasm for Star Wars and Close Encounters of the Third Kind," and proposed that SETI should be "postponed a few million light-years." ${ }^{27}$ While Proxmire was often criticized for being ill-informed about the recipients of his Golden Fleece Award, he regularly was able to terminate funding for the projects he honored. SETI continued to receive some NASA funding, but, not wanting to threaten the more important and much more expensive space programs, NASA kept SETI funding below the Congressional radar.

However, the Golden Fleece award sparked a decades-long battle over NASA and even NSF funding for SETI projects. While strong scientific and public support successfully rebutted Proxmire's legislative attacks on proposed funding, the continuing struggles over NASA funding prompted Tom Pierson and Jill Tarter to create the private SETI Institute and Bruce Murray and Carl Sagan to form the Planetary Society, both of which could operate at lower cost than a government agency such as NASA. By the mid-1980s, following the urging of Carl Sagan, Proxmire relented, apparently leaving SETI with no strong opponents in Washington (Drake and Sobel 1992, pp. 195-196), and encouraging NASA to develop the SETI Microwave Observing Project (MOP). Subsequently, NASA established the MOP much in the same way as other NASA missions, issuing a "Research Announcement" soliciting proposals for several facility instrumentation teams as well as the usual Interdisciplinary Investigators. A project office was set up at Ames and began negotiations with NRAO for NASA to take over the operation of the 140 Foot full time for SETI beginning in 1995 when the new 100 meter GBT was expected to be completed (See Chap. 10).

The Microwave Observing Project, which was later renamed the High Resolution Microwave Survey (HRMS) consisted of two complementary strategies: the NASA Ames based Targeted Search System (TSS) and the JPL based Sky Survey (Dick 1993). The TSS was planned to use primarily the Green Bank 140 Foot, the Parkes 210 foot, the Nançay 94 meter, and the 1000 foot Arecibo radio telescopes to examine 800 nearby stars between 1 and $3 \mathrm{GHz}$, 
while the Sky Survey planned to use the antennas of JPL's Deep Space Tracking Network in California, Australia, and Spain to search the entire sky between 1 and $10 \mathrm{GHz}$. Each project developed its own wide bandwidth spectrum analyzer with up to 30 million independent frequency channels having a resolution as narrow as about $\mathrm{l} \mathrm{Hz}$. The NASA HRMS was formally launched on 12 October 1992 (500 years after Columbus landed in the Bahama Islands) with simultaneous celebrations at the JPL Goldstone Deep Space Communications Complex in California and at the Arecibo Observatory in Puerto Rico. Ironically, although the engineers at Goldstone and Arecibo were looking for signals originating from many light-years away, they were unable to get the planned communications link between the two US sites to work.

After only a year of full funding, the HRMS and all US SETI research suffered a major setback. The HRMS project was projected to cost \$108 million spread over about a decade, and was vigorously promoted in Washington by Jill Tarter and others. Congressional lobbying can sometimes be successful in raising funds for a pet project, and usually at worst is ignored. Typically, a ten million-dollar budget item in NASA's then seven billion-dollar annual budget would go unnoticed by Congress, or perhaps would be buried somewhere and not even appear as a line item. But the broad public interest in SETI along with the intense lobbying effort brought the HRMS to the attention of Democratic Senator Richard Bryan from Nevada. Bryan, the former governor of Nevada and a long-standing opponent of SETI, had unsuccessfully tried to kill the NASA SETI program for FY1992 and FY1993, perhaps in an attempt to get visibility for himself and the state of Nevada. On 20 September 1993, Bryan introduced a late amendment to the 1994 Housing and Urban Development appropriations bill to "prohibit the use of funds for" NASA's \$12 million HRMS funding appropriation. Only the previous day, in a Parade Magazine article, ${ }^{28}$ Carl Sagan had inadvertently provided fuel for Bryan's anti-SETI rhetoric. Sagan's article started out by specifically drawing attention to the year-old NASA SETI program and tried to minimize the cost by comparing it to the price of a military attack helicopter. Sagan's article was widely distributed as a supplement to the 19 September Sunday newspapers around the country, and almost certainly came to the attention of Bryan, who introduced his amendment the following day. Referring to SETI as "The Great Martian Chase," Bryan went on to absurdly state, "As of today millions have been spent and we have yet to bag a single little green fellow. Not a single Martian has said take me to your leader, and not a single flying saucer has applied for FAA approval. $" 29$

Bryan argued that he was not against science, but pointed out that the previous year both the House and Senate had eliminated NASA's MOP. He was clearly annoyed that NASA had adopted the new HRMS name, which he felt was a weak attempt to hide SETI funding. He argued that even after decades, SETI had never detected any signs of intelligent life and that \$12 million could send 9000 needy students to the University of Nevada. ${ }^{30}$ Despite a valiant effort from Senators Barbara Mikulski (D-MD), Phil Graham (R-TX) and Jay 
Rockefeller (D-WV), two days later by a voice vote, the Senate passed Bryan's amendment to save taxpayers money, and NASA's HRMS program died on the Senate floor.

Having just rebounded from the Hubble Space Telescope spherical aberration mirror fiasco, ${ }^{31}$ NASA was not in a strong position to argue with Congress for SETI funding. Formally the funding bill applied only to NASA's 1994 budget, but NASA was not willing to incur Congressional wrath and fight over this relatively small budget item that was out of the mainstream of NASA programs. Much of the previous effort and expenditures of approximately $\$ 15$ million at Ames and at JPL had gone into designing and prototyping several generations of high resolution multichannel spectrometers and other instrumentation. So there were few actual observations to use as a basis for soliciting additional funding. For more than a decade following Senator Bryan's intervention, SETI was an unpopular subject at NASA and at other government agencies such as the NSF, where SETI research was explicitly excluded from NSF grants until 2000. Nevertheless, NRAO continued to support modest SETI programs on the 140 Foot and 300 Foot Telescopes, provided they were not given undue publicity and the results would be published in the normal astronomical journals rather than the popular literature.

It was perhaps unfortunate that the national SETI program had become so entwined with NASA, primarily because some of the key people interested in SETI research happened to already work for NASA. Unlike the NSF, NASA has historically concentrated on big missions in space with well-defined realistic goals, and has not looked favorably on ground-based research. SETI as an ongoing research activity with constantly changing procedures and goals was probably more appropriate for the NSF than NASA. Ironically, SETI's association with NASA created the image within the astronomy community that SETI, like other NASA programs, had generous funding, at least in comparison with NSF funded research programs.

SETI Goes Private Jill Tarter and other SETI researchers have repeatedly pointed out SETI's awkward situation: SETI is one of those scientific endeavors that must justify additional expense for increased capability on the basis of previous failures (e.g., Garber 1999). Fortunately, Tarter and others have been able to exploit the extensive instrumentation development begun by the HRMS and prior NASA SETI programs. Supported largely by private funding, the SETI Institute initiated Project Phoenix to search the $\sim 800$ nearby stars originally specified by the HRMS Targeted Search. Phoenix used nearly 30 million simultaneous $1 \mathrm{~Hz}$ spectral channels and had the capability to detect signals in the range between 1 and $3 \mathrm{GHz}$ which might have originated from transmitters comparable to the most powerful terrestrial radars such as those at Arecibo and Goldstone. Following an extensive negotiation with NRAO, the SETI Institute purchased time on the Green Bank 140 Foot Radio Telescope for Project Phoenix. But after nearly a decade of searching with the 140 Foot 
Telescope, as well as the Parkes, Nançay, and Arecibo radio telescopes, no convincing signals from any extraterrestrial civilizations were detected.

Three other long running SETI programs need to be mentioned. ${ }^{32}$ Using private funding, SERENDIP or the "Search for Extraterrestrial Radio Emissions from Nearby Developed Intelligent Populations," used a secondary feed for so-called commensal or "piggy-back" research, primarily at Arecibo and Green Bank, to examine random directions in the sky determined by the regularly scheduled astronomical program being pursued at the telescope. SERENDIP, which went through a series of four hardware and software upgrades, used as many as 168 million channels to cover a $200 \mathrm{MHz}$ wide band.

At Ohio State University, following the completion of their all sky radio source survey in 1973, Robert Dixon and John Kraus initiated a SETI survey using their standing parabolic reflector which Kraus referred to as "Big Ear." Kraus also self-published a journal called Cosmic Search, which promoted a variety of SETI programs as well as provided a broad introduction to topics in radio astronomy. ${ }^{33}$ Aside from a widely publicized but never confirmed "WOW" signal recorded on 15 August 1977, Big Ear found no signs of any signals originating from any extraterrestrial civilizations. ${ }^{34}$ The program ran for many years using largely student and volunteer labor, until the telescope was finally shut down. In 1998, despite widespread popular protest, Big Ear was removed to build a golf course.

A particularly innovative SETI activity has been the SETI@home program developed by Dan Wertheimer and colleagues at the University of California, Berkeley. SETI@home uses data taken at a number of the world's most powerful radio telescopes which is then is distributed over the internet to more than 80 million personal computers in more than 200 countries around the world where the data is analyzed for evidence of signals not of natural origin and not due to terrestrial interference. The combined computing power of the distributed SETI@home network, which operates on the host computers as a screensaver, rivals that of the world's largest super computers and has resulted in tens of millions of amateurs involved in what must be the largest citizen science programs ever implemented. However, the amateur SETI effort has not been confined to data analysis, as a number of amateurs have built modest facilities which they have used to survey the sky for signals from extraterrestrial civilizations. Many of these amateur activities are coordinated by the SETI League which has more than one thousand members.

Naturally, there were many false alarms, perhaps the most dramatic being Jocelyn Bell's 1967 discovery of pulsars. After eliminating the possibility that the pulsating signals had a terrestrial origin, but noting that the pulsars had all the characteristics of terrestrial radar systems, Cambridge radio astronomers wistfully speculated that they might be observing interstellar beacons used to guide interstellar travel, and whimsically named them Little Green Men or LGMs (Bell 1984). Even earlier, Gennady Sholomitsky (1965) used a classified Soviet military facility in Crimea (Fig. 5.5) to observe the radio sources CTA 21 and CTA 102 which were known to have peculiar radio spectra (Kellermann 


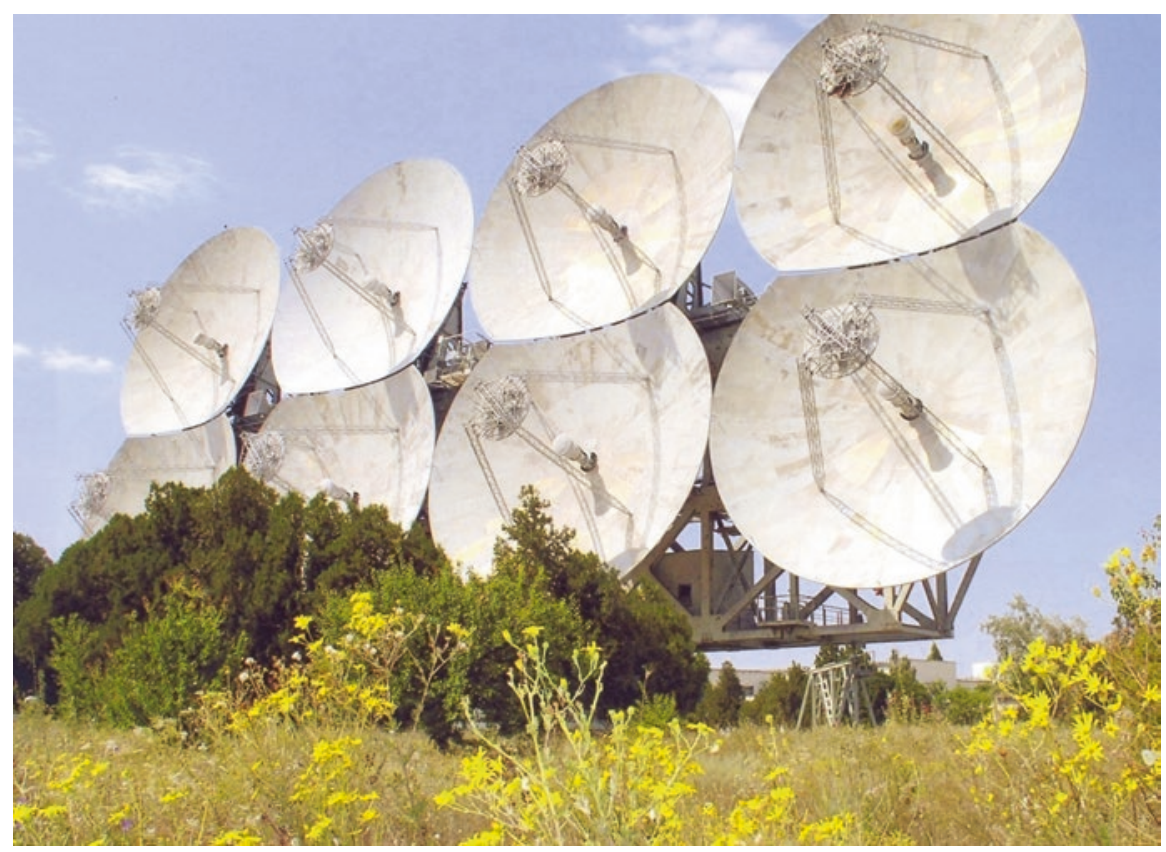

Fig. 5.5 The ADU-1000 antenna at the Evpatoria Deep Space Communication and Control Center in Crimea used by Gennady Sholomitsky in 1964 and 1965 to observe CTA 102. The array of eight 16 meter diameter antennas was built from parts of a Soviet battleship, a military railway bridge, and the hull of a captured Italian submarine. Credit: State Space Agency of Ukraine

et al. 1962). Sholomitsky, who was a student of the Russian astrophysicist Iosef Shklovsky, made the surprising discovery that over a period of only a few months, the strength of the radio source CTA 102 changed by about 30 percent (Sholomitsky 1965) (Fig. 5.6). It was difficult to explain such rapid variability in terms of what was then understood about synchrotron radiation from radio galaxies and quasars. ${ }^{35}$ On 12 April 1965 Alexander Midler, a TASS (Soviet equivalent of the Associated Press) science reporter, overheard a discussion between Shklovsky and Nikolai Kardashev speculating that perhaps the observed radio emission from CTA 102 might have been generated by an extraterrestrial civilization, and later that day, TASS issued a "telegram" on the discovery by Soviet scientists of an artificial cosmic signal. At a large press conference widely attended by Soviet as well as foreign press, Shklovsky and Kardashev, playing with the assembled journalists, did not deny the possibility that the signals from CTA 102 were due to an extraterrestrial intelligence (Fig. 5.7). The press took it seriously, and the 14 April 1965 issue of Pravda reported that extraterrestrials were signaling the Earth. The startling news quickly spread to newspapers throughout the Soviet Union and around the 


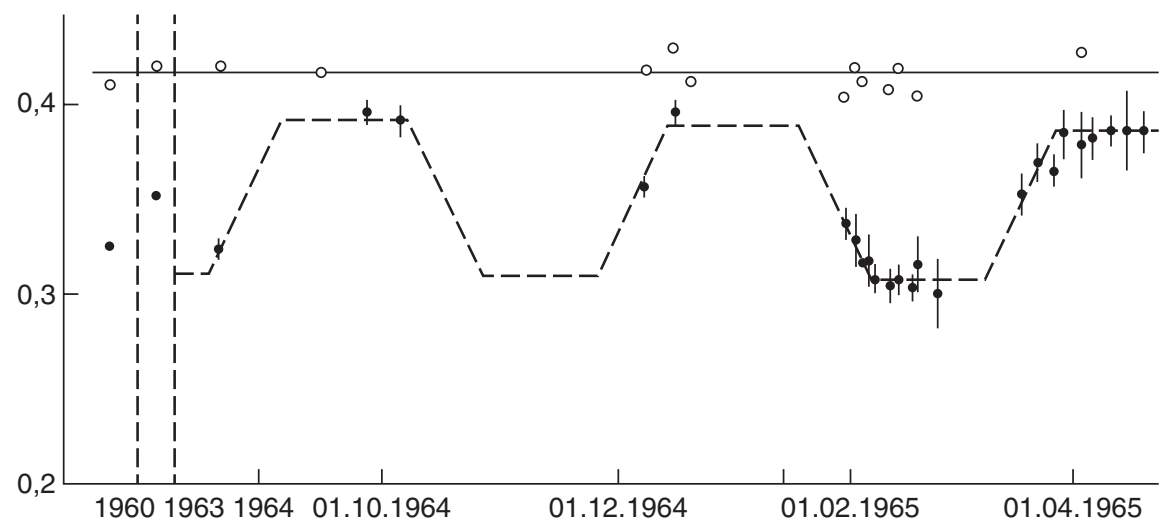

Fig. 5.6 Variability of CTA 102 from late 1963 to mid-1965 as it appeared in Pravda. Filled circles show the flux density of CTA 102 relative to 3C 48. The open circles are for CTA 21. Credit: Courtesy of the Sholomitsky family

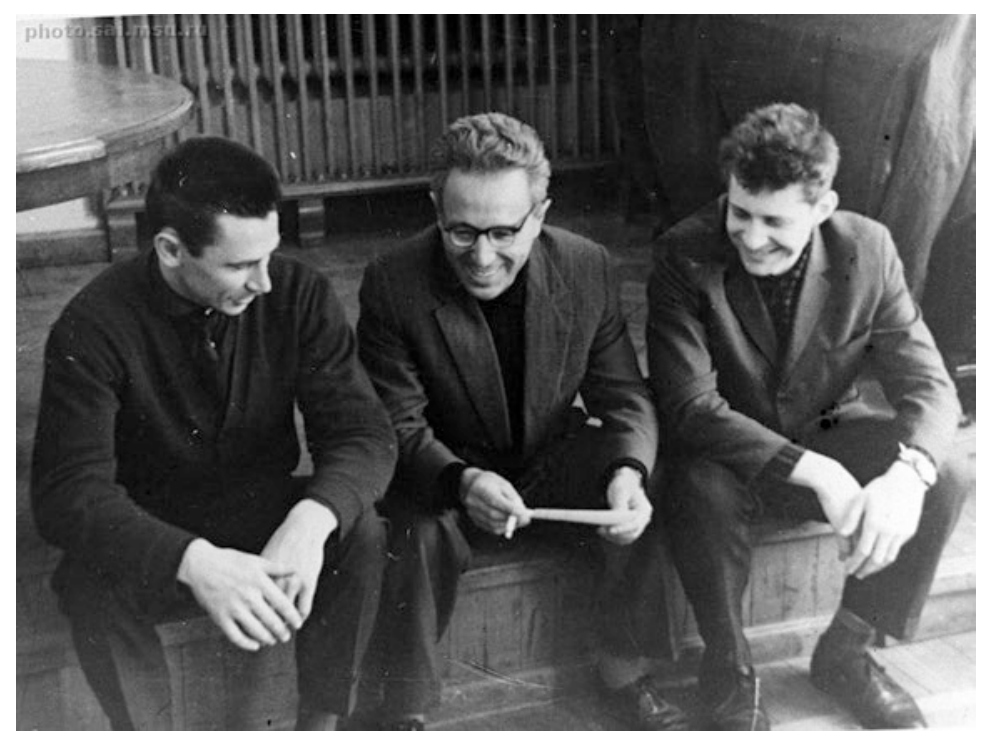

Fig. 5.7 From left to right, on the steps of Moscow State University, Gennady Sholomitsky, Josef Shklovsky, and Nikolai Kardashev having a good laugh following the 12 April 1965 press conference. Credit: Courtesy of Sternberg Astronomical Institute, Moscow State University

world. The Byrds, a famous rock group, popularized a song about extraterrestrials from CTA 102 that even entered the peer reviewed scientific literature. ${ }^{36}$

Approaching the close of the twentieth century, the SETI Institute inaugurated a new study to review the status of SETI and plan for the future. Over an 18-month period in 1998 and 1999, the SETI Science and Technology 
Working Group (SSTWG), led by Australian radio astronomer Ronald Ekers, met on four occasions to develop a strategy for both the near term as well as the long term opportunities for SETI. The Working Group report confirmed that searches in the electromagnetic spectrum should continue including optical as well as radio wavelengths; that both targeted and sky surveys are needed; that telescopes be developed with multiple beams; that searches include both narrow band signals as well as broad band pulsed emissions; that the focus should be on the detection of beacons, but although thought to be less likely, the eavesdropping scenario should not be excluded; and that multiple site detection systems be used to discriminate against terrestrial interference, thus greatly improving the credibility of the search (Ekers et al. 2002).

An important outcome of the SSTWG study, the impact of which went well beyond SETI, was the development of the Large-N-Small-D (LNSD) concept to build up a very large collecting area by using many small, possibly commercially available dishes and receivers, instead of a single large aperture. The SSTWG recommended the construction of the One hectare Radio Telescope (lhT) which later became the basis of the proposal to build the Allen Telescope Array. The LNSD concept was further developed by the US Square Kilometre Array (SKA) Consortium as part of a proposal from the United States to build the International SKA, consisting of thousands of 12 meter class dishes spread throughout the western United States. The United States later withdrew from the SKA project, but the International SKA mid-frequency design, which plans to include first hundreds then thousands of 15 meter ( 49 foot) diameter antennas to be erected at a remote site in South Africa, is also based on the LNSD concept developed by the SETI Institute's SSTWG (Sect. 11.7).

With the less than enthusiastic interest in SETI at NASA and at the NSF, US SETI activities have depended more and more on growing private philanthropy. In addition to the modest donations from thousands of individuals, people such as Bernard Oliver from Hewlett Packard, Microsoft co-founder Paul Allen, and Nathan Myhrvold, who made his fortune as Chief Technology Officer at Microsoft, generously supported the search for extraterrestrial civilizations. A potentially major advance to SETI research came from Paul Allen's gifts amounting to $\$ 30$ million to construct the first radio telescope specifically dedicated to the Search for Extraterrestrial Intelligence. The Allen Telescope Array (ATA) was expected to include 350 six meter diameter dishes to obtain a total collecting area of about 10,000 square meters-roughly the equivalent of a 100 meter diameter steerable dish antenna. The monolithic parabolic reflecting surface of each antenna was designed to be stamped out from a single mold instead of the conventional construction method using a large number of small panels. However, the design and construction of the antenna structure and the associated electronics proved to be more complicated and more expensive than anticipated, so the available funds only permitted the construction of 42 of the originally planned 351 antennas or $12 \%$ of the planned collecting area.

The ATA, which is located at the Hat Creek Radio Observatory in northern California, began operation in 2007. As has been the case for many modern 
radio telescopes, especially in the United States, operating funds turned out to be even more difficult to raise than construction funds. Following a brief funding hiatus in 2011, the ATA has been operated by SRI International with support largely from the US Air Force for a variety of programs, including SETI as well as conventional radio astronomy, to complement several Defense Department programs.

\subsection{SETI IN THE USSR}

Interestingly, outside of the United States, it was primarily scientists in the Soviet Union, inspired by the imaginative astrophysicist Iosef Shklovsky, who have been seriously involved in SETI research. ${ }^{37}$ Unlike the American programs which concentrated on high spectral resolution to look for very narrow band radio signals, the Soviet effort, largely led by Vsevolod Troitsky, considered broad band very short time duration pulses as well as monochromatic radio emissions. ${ }^{38}$ (See Troitsky et al. 1971, 1974). On the theoretical side, Nikolai Kardashev's famous paper on Type I, Type II, and Type III civilizations focused on the development of civilizations based on their ability to harness the energy from their planet, their sun, and their galaxy respectively (Kardashev 1964). Kardashev also argued that the broad spectral region near the $1421 \mathrm{MHz}$ hydrogen line had minimum noise and so was optimum for SETI research.

Characteristically, the Soviet SETI program was more structured than its American counterpart. Like much scientific research in the USSR, especially if related to electronics, computers, or other high tech instrumentation, there was a significant government component, generally through the Soviet Academy of Sciences. Drake even remarked,

I believe ... it had little to do, in my opinion, with a wide regard for the search enterprise itself, but was more of a reflection of the state of Soviet science in general, particularly the lack of peer review. There was also a political motive behind the government support for these activities: The authorities correctly perceived the search enterprise as an area where Soviets could compete with and possibly excel over American efforts (Drake and Sobel 1992, p. 96).

Following Project Ozma, in 1964 Soviet astronomers met at the Armenian Byurakan Astrophysical Observatory for the Soviet National Conference on Problems of Communication with Extraterrestrial Civilizations to set out a plan for future SETI research (Tovmasyan 1964). This early Soviet conference was a remarkable preview of SETI conferences that would be held over the course of the next half century and included speculations on the multiplicity of inhabited worlds, the existence of alien civilizations at various levels of development, the best means for establishing communication, how to distinguish an extraterrestrial signal sent by an advanced alien civilization from terrestrial interference, as well as the problems of linguistics. The conference concluded 
that it would be appropriate to begin a simultaneous program of transmission and reception of radio signals. Reacting to skepticism about transmitting, Shklovsky argued that starting to transmit was like burying a time capsuleonly more expensive.

In 1972 the Soviet Academy considered and approved a national research program on "Communication with Extraterrestrial Civilizations" (Scientific Council of the USSR Academy of Sciences 1975). The intended Soviet program included targeted searches and all sky surveys at both radio and infrared wavelengths, searches for monochromatic signals as well as broad band pulses, and noted the need for special attention to develop the techniques that would be needed to decipher any received signals. Interestingly, however, there was no mention of transmitting in the 1972 plan.

In a noteworthy departure from the Cold War atmosphere of the time, in May 1971 scientists from the USSR and the US gathered at the Byurakan Observatory in Soviet Armenia for the first ever international conference about the search for extraterrestrial intelligence (Fig. 5.8). The Byurakan conference,

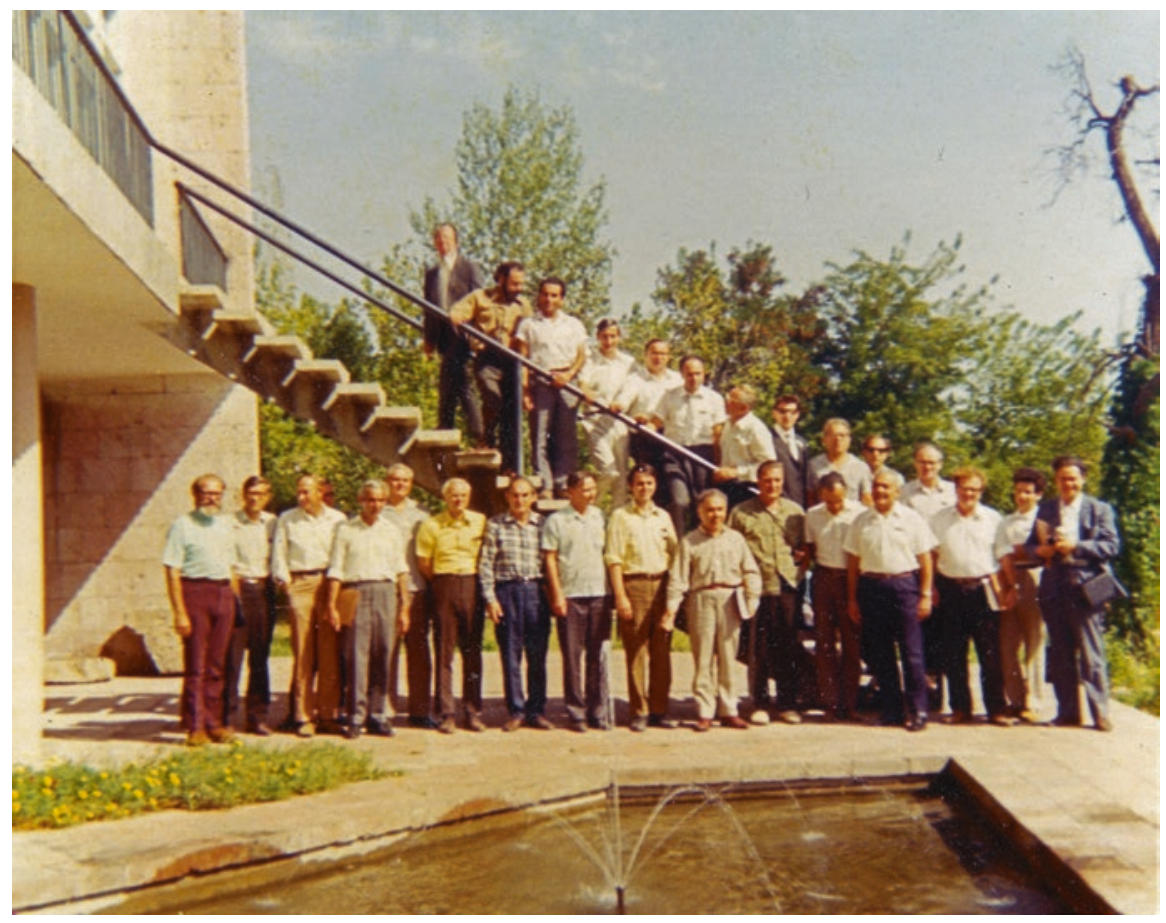

Fig. 5.8 Participants in the 1971 US-USSR SETI Symposium at the Armenian Byurakan Observatory. One of the present authors (KIK) is standing in the back 5 th from the right wearing dark glasses. Standing in the front are Frank Drake (6th from left), Vitaly Ginzburg (7th from left), Carl Sagan (9th from left). Credit: KIK/NRAO/ AUI/NSF 
which was co-sponsored by the Soviet and US Academies of Science, was remarkable in bringing together scientists from a wide range of disciplines, including anthropology, linguistics, biology, and world history as well as astrophysics and SETI, to discuss the scientific basis for intelligent life elsewhere in the Universe; the technical and sociological challenges of SETI; and the moral, social, and legal implications of a successful detection. Critical to the meeting was Boris Belitsky, who served as the incredible bilingual nearly real-time translator. Belitsky was born in the United States and grew up in the Soviet Union with his parents who had emigrated in the 1930s. He was the English language science editor for Radio Moscow and had served as the translator at the 1960 trial of Francis Gary Powers after his U-2 spy plane was shot down by a Soviet missile over Soviet territory. ${ }^{39}$

The Byurakan conference confirmed that the search for extraterrestrial intelligence was technically feasible; that a successful detection would have a profound influence on the future of civilization on Earth; that a successful search would likely require a large expenditure of funds and resources, but that a modest start was feasible and was recommended. The group also made some specific recommendations for future work to search for civilizations not only at our own level of technical development, but also at a "level greatly surpassing our own" and discussed building "a decimeter radio telescope with an effective area $\geq 1 \mathrm{~km}^{2}$." The recommendations included searches for narrow band signals, but also for strong impulsive signals from both ground and in space, and set the agenda for SETI research for the next decades. ${ }^{40}$ Two later meetings of USSR and US SETI scientists were held in Tallinn, Estonia in 1981 (Sullivan 1982) and in Santa Cruz, California in 1991, although by the time of the Santa Cruz meeting SETI research had all but ceased in the rapidly crumbling USSR $^{41}$ (See Shostak 1993).

\subsection{Continuing SETI Programs}

The Soviet focus on the evolution of civilizations mirrored the development of SETI in the United States in the 1950s and 1960s. With time and the progress of astronomical research, the rate of star formation in the Galaxy, the fraction of stars with planets, and the number of habitable planets were reliably estimated, even measured, and is now known to be very large. Thus, the biggest uncertainty about the number of advanced communicative civilizations is still the formation and longevity of intelligent civilizations. But even as early as his 1961 lecture at the Philosophical Society of Washington, Drake commented, ${ }^{42}$

The number of civilizations with which we might communicate today is strongly affected by the average length of time during which technology and motivation allow a civilization to be contacted. We have a very poor estimate of this time at present, with a resultant large uncertainty in the number of civilizations we might contact. 
Our increasing recognition of the ubiquity of planets around other stars in the Galaxy, combined with the improvement by many orders of magnitude of the sensitivity of SETI programs and the lack of any positive detections, has raised a concern for the future of humanity. As early as 1950, Enrico Fermi is said to have famously asked, "Where is Everybody?" 43 leading to many speculations ranging from the motivations of extraterrestrials to a worrisome short value of $L$ due to the inevitable self-destruction of technological civilizations, whether from war or environmental negligence. The scientific debate over the lifetime of civilizations echoed the vociferous debates over nuclear weapons during the Cold War period. The threat of global annihilation particularly impacted US and Soviet SETI scientists, perhaps motivating them to better understand our place in the Universe and the lifetime of our own civilization. Indeed, at the Green Bank 25th anniversary Project Ozma celebration, Sebastian von Hoerner, who had served in the German army on the Russian front and later lived through the 1945 Allied destruction of Dresden, explained that the aftermath of Dresden was "much more gruesome" than any fictional apocalypse, and that it will be not the day after a nuclear war but "it is the year after, when all of the food has been eaten up and when the thin skin of our civilization comes peeling off in large chunks." (von Hoerner 1985, p. 3).

In 2016, Frank Drake and SETI returned to Green Bank. Yuri Milner, a Russian billionaire, has pledged $\$ 100$ million over a ten-year period to support SETI investigations at the Green Bank Telescope, the Parkes 210 foot dish, the 500 Meter FAST fixed radio telescope in central China, and elsewhere. Milner's Breakthrough Listen project will search a million Galactic stars and 100 nearby galaxies. This project is led by former Air Force General Pete Worden, the former Director of the NASA Ames Research Center and one of the leaders of President Ronald Reagan's Strategic Defense Initiative (also known as Star Wars), with the support of Frank Drake, Sir Martin Rees, and the late Stephen Hawking. Milner started out studying physics at Moscow State University. Apparently his teacher, Andrei Sakharov, was not impressed with Milner's promise in physics, and suggested that he might consider a different career. This inspired Milner to study business at the University of Pennsylvania and to go on to a very successful career in finance. More than half a century after Frank Drake's Project Ozma, with Milner's generosity, Green Bank is again probing the skies for signals from extraterrestrial intelligent civilizations, but with more than a million times better sensitivity than Project Ozma. Thus Breakthrough Listen can detect in one second a signal that would have taken Project Ozma 100,000 years. On the downside, the radio spectrum is vastly more polluted now than it was more than half a century ago for Project Ozma. Today, SETI has to deal with the proliferation of interfering signals from commercial, military, and scientific satellites, as well as from a wide range of terrestrial transmissions, interference which will only get worse with time.

In the more than half-century since Project Ozma, a small group of dedicated enthusiasts such as Kardashev, Oliver, Drake, Bracewell, Kraus, Morrison, and later Tarter have remained passionate about the need to search for alien 
intelligence. Others such as University of Virginia's Robert Rood, Shklovsky, and von Hoerner later became disillusioned about the prospects for a successful detection, while yet others saw SETI as a backdoor approach to fund new large radio telescope systems, or to protect the radio spectrum from interference. Further, the continued lack of any observational evidence for extraterrestrial civilizations has led to serious objections from some about the justification for SETI research. Others, such as the SETI Institute's Jill Tarter (2010), point out that only a very small amount of the nine-dimensional "cosmic haystack" ( 3 directions, time, frequency, modulation, sensitivity, and 2 polarizations) has been searched for the illusive needle in the cosmic haystack. Sir Martin Rees famously pointed out, "The absence of evidence is not evidence of absence," (Oliver and Billingham 1973, p. 3) a remark arguably made even more famous by Carl Sagan in defense of his continued support for SETI. Starting with Drake's Project Ozma, NRAO has treated proposals for SETI the same as more conventional astronomical research programs. While there was no secrecy, neither was there any undue publicity associated with the NRAO SETI proposals. Even during the period when the NSF would not entertain grant proposals for SETI, NRAO continued to support modest SETI proposals on the 140 and 300 Foot Telescopes. Considering that the proposed NASA SETI program amounted to less than 0.1 percent of the NASA budget, one cannot help but wonder whether, if there had been less publicity and lobbying by the NASA SETI researchers, they might have escaped the scrutiny of Congress.

Probably no other subject in the history of science has had more conferences held or books published based on the absence of any experimental results. Indeed, it is hard to think of any other area of human inquiry where we know less about what we are looking for, where to look, how to look, or even if there is anything to look for. Astronomers know much more about the planets, stars, and galaxies than about the technology and motivation of extraterrestrials, but as discussed in Sect. 6.2, astronomers did not do a very good job of predicting cosmic masers, pulsars, quasars, solar and Jupiter radio storms, gravitational lenses, the cosmic microwave background, the rotation of Mercury and Venus, or indeed cosmic radio emission itself, until they stumbled across them in the course of other investigations, some of which were motivated by commercial and military goals or as demonstrations of national strength and prestige. SETI search strategy is an interesting intellectual exercise, but may not lead to anything. The first detection of an intelligent communicative extraterrestrial civilization may well come from a similar serendipitous discovery, perhaps even by an amateur, rather than a directed SETI investigation. Nevertheless, there is universal agreement, as argued in the National Academy of Science 1991 Decade Review of astronomy that, "A successful 'contact' would be one of the greatest events in the history of mankind." (Bahcall 1991b, p. I-13). 


\section{Notes}

1. ROTC is the Reserve Officers Training Corp, a university program to train military officers. ROTC students received a stipend to cover their education expenses toward a four year degree in return for a commitment to serve in the active military.

2. Drake was recruited by Dave Heeschen and joined NRAO on 1 January 1958 but spent the first few months finishing up his $\mathrm{PhD}$ thesis at Harvard and planning the 85 foot research program. For further information about Drake's childhood and education see Chap. 1 in Drake and Sobel (1992).

3. We will use SETI throughout this chapter to refer to both individual projects and the general field of research dealing with the detection of radio signals from extraterrestrial civilizations. The term SETI came into common use in the 1970s. Throughout the 1960s scientists referred to the various components of what became known as SETI by many names including interstellar signals, communication with extraterrestrial life, communicative civilizations. The term SETI can originally be traced back to the 1971 Communication with Extraterrestrial Intelligence (CETI) Conference held at the Byurakan Astrophysical Observatory in Armenia. At the conference, Drake, Kardashev, and Shklovsky acknowledged that you first have to find extraterrestrials before you can communicate with them. The phrase "search for extraterrestrial intelligence" first appears in Project Cyclops (Oliver and Billingham 1973), the 1972 NASA study on detecting extraterrestrial intelligent life. Another NASA study led by Phil Morrison in 1977 on the same topic was the first to use SETI as an acronym. SETI quickly became the standard terminology of the field.

4. The Zeeman effect results from a magnetic field which splits the $21 \mathrm{~cm}$ line of neutral hydrogen into multiple lines. Since the separation of the lines is proportional to the magnetic field strength, the Zeeman effect can be used to determine the magnetic field strength in hydrogen clouds.

5. Epsilon Eridani is now known to have at least one planet, known as Epsilon Eradani b, which orbits the star with a period of 6.85 years. However, Epsilon Eradani b has a mass about 1.5 times that of Jupiter and so may be unable to support any kind of life (Benedict et al. 2006).

6. Pulsars were unknown at the time, see Kellermann and Seielstad (1986), p. 25.

7. Otto Struve, Karl Taylor Compton Lecture Series, MIT Libraries, Institute Archives and Special Collections.

8. Actually, the Cocconi and Morrison paper was already published in the 19 September issue of Nature, but a copy had not yet reached Green Bank.

9. Drake to Paine (NSF), 19 October 1959, NAA-NRAO, DO, Conferences, Symposia, and Colloquia.

10. New York Times, 22 November 1960, p. E 11.

11. Indeed, a small band centered on the $1420.4 \mathrm{MHz}$ hydrogen line is the only globally protected frequency on Earth.

12. Between the $1.4 \mathrm{GHz}$ hydrogen line and the $1.7 \mathrm{GHz} \mathrm{OH}$ hydroxyl line is the water $\left(\mathrm{H}+\mathrm{OH}=\mathrm{H}_{2} \mathrm{O}\right)$ hole.

13. Near Roswell, New Mexico, beginning on 7 July 1946, local ranchers found debris from a crash, and the US military quickly launched an effort to recover the debris. The official explanation of the event attributes this debris to the collapse of a military surveillance balloon. However, the more popular explanation 
attributed the debris to a downed spaceship that contained alien life, which the US government covered up with their official version of the events. The Roswell UFO incident, as it was called, became the most famous supposed UFO encounter, though the 1950s and 1960s marked a high point in reports of such phenomena. For information on the Roswell Incident and encounters with extraterrestrial life, see Clark (1993).

14. Pearman to Villard, 13 March 1961, NAS-NRC-A, Organized Collections, SSB, Conferences, Extraterrestrial Intelligent Life.

15. Drake to Pearman, 13 March 1961, NAS-NRC-A, Organized Collections, SSB, Conferences, Extraterrestrial Intelligent Life.

16. Pearman to File, 9 June 1961, NAS-NRC-A, Organized Collections, SSB, Conferences, Extraterrestrial Intelligent Life.

17. Letter of invitation to the Green Bank conference from Otto Struve to approximately 20 invitees, NAA-NRAO, DO Conferences, Symposia, Colloquia.

18. People like Heinrich Hertz, Guglielmo Marconi, Nicola Tesla, Donald Menzel, and even Albert Einstein considered methods to communicate with extraterrestrials, particularly Martians.

19. See Pearman (1963) for a discussion of the 1961 Green Bank SETI Conference.

20. A webcast of the 2010 conference is available at https://vimeo.com/ album $/ 3095975$

21. Sullivan interview of Drake, 27 April 1979, NAA-WTS, Individuals. https:// science.nrao.edu/about/publications/open-skies\#section-5

22. A non-binding protocol that recommends how the detection of extraterrestrial intelligence should be disseminated was authored by the International Academy of Astronautics and the International Institute of Space Law, and now has been adopted by a group of individuals and institutions participating in the search for extraterrestrial intelligence. http://www.seti.org/post-detection.html. However, like many other well-intentioned agreements, it was not signed by all potential signal recipients and, in any event, is not enforceable.

23. Part of the House Committee on Science and Technology.

24. The Library of Congress Science Policy Research Division, later known as the Congressional Research Service, provides bipartisan information to Congress.

25. Tarter et al. (1980) used the NRAO VLBI recording system (see Sect. 8.4) to digitally record a $360 \mathrm{kHz}$ IF band which they subsequently analyzed in a CDC 7600 computer. In this way they were able to create an early form of postobservation Digital Signal Processing to implement a multichannel spectrometer with more channels and narrower bandwidths than then possible with conventional analogue hardware.

26. Probably the true cost of building Cyclops would have vastly exceeded the $\$ 10$ billion estimate given in the Cyclops report, which was only $\$ 10$ million per $100-\mathrm{m}$ antenna exclusive of instrumentation. For the VLA, the cost of the instrumentation was about twice the cost of the antenna elements.

27. Press release from Senator William Proxmire, 16 February 1978.

28. "The Search for Signals from Space," Parade Magazine, 19 September 1993.

29. Senator Richard Bryan Press Release, 22 September 1993.

30. Congressional Record, 20 September 1993.

31. When launched in 1990 after more than a decade of development and huge cost overruns, the Hubble Space Telescope mirror was found to have been incorrectly ground, resulting in badly defocused images. 
32. For a full list of SETI projects undertaken between 1959 and 1992 see Drake and Sobel (1992).

33. Between 1979 and 1982 John Kraus and his students published 4 volumes of Cosmic Search.

34. On 15 April 1977 Big Ear registered a short lived but strong signal, characteristic of a cosmic rather than terrestrial origin. When looking later at the recorded telescope output chart, Jerry Ehman wrote, "Wow." See Grey (2012).

35. The argument went that if a radio source varied on a time scale of 100 days it could not be more than 100 light days across, otherwise the signals from different parts of the source would arrive at different times and the variability would be smeared out. In such a small source, the density of relativistic electrons responsible for the observed synchrotron radiation would be so great that the radiation would be self-absorbed and not able to escape the source.

36. In 1968, after receiving the referee's report, Eugene Epstein of the Aerospace Corporation sneaked a note about the Byrds' CTA 102 song into their Astrophysical Journal paper about radio source variability. See Schorn et al. (1968). One of the present authors (KIK) was the referee of this otherwise serious publication.

37. In 1960, Shklovsky wrote a stimulating article in the Soviet journal Priroda, No. 7,21 which was reprinted in Interstellar Communication, ed. A. G. W. Cameron (New York: W. A. Benjamin), p. 1.

38. Other related programs involved the Moscow Power Institute, the All-Union Electrical Engineering Institute of Communications, the Russian Language Institute, and the USSR Academy of Sciences.

39. Powers was flying over the USSR as part of a CIA mission to monitor Soviet nuclear weapons development. Unexpectedly, his U2 aircraft was shot down by a Soviet missile on 1 May 1960; Powers survived and was taken prisoner by the KGB. President Eisenhower, not knowing that Powers had survived, initially claimed that it was a weather plane that had drifted off course. Powers was tried and found guilty of spying, but was returned to the US in exchange for Soviet spy Rudolf Abel. Powers later died in a helicopter crash while reporting on Los Angeles traffic for a local TV station.

40. Reports of the 1971 US-USSR CETI Conference, which was attended by one of the authors (KIK), are given in a short report by the Organizing Committee, chaired by V.A. Ambartsumian (1972) and in a colorful article written by Freeman Dyson (1971).

41. The Third Decennial US-USSR Conference on SETI was held in August 1991, just a week prior to the ouster of the USSR leader Mikhail Gorbachev that led to the collapse of the USSR five months later.

42. Frank Drake, "Detection of Extraterrestrial Intelligent Life," Washington Philosophical Society, Smithsonian Institution Archives, Washington, DC. We are grateful to Steven Dick for providing us with copies of the records of Drake's talk.

43. This is known as "The Fermi Paradox." 


\section{BIBLIOGRAPHY}

\section{REFERENCES}

Ambartsumian, V.A. 1972, First Soviet-American Conference on Communication with Extraterrestrial Intelligence (CETI), Icarus, 16, 412

Bahcall, J. ed. 1991a, The Decade of Discovery in Astronomy and Astrophysics: Report of the Radio Astronomy Panel (Washington: National Academy Press)

Bahcall, J. ed. 1991b, Working Papers: Astronomy and Astrophysics Panel Reports (Washington: National Academy Press)

Bell Burnell, J. 1984, The Discovery of Pulsars. In Serendipitous Discoveries in Radio Astronomy, ed. K.I. Kellermann and B. Sheets (Green Bank: NRAO/AUI), 160 http://library.nrao.edu/public/collection/02000000000280.pdf

Benedict, G.F. et al. 2006, The Extrasolar Planet $\varepsilon$ Eridani b: Orbit and Mass, AJ, 132, 2206

Billingham, J. 1990. In SETI Pioneers: Scientists Talk About Their Search for Extraterrestrial Intelligence, ed. D.W. Swift (Tucson: University of Arizona Press), 246

Clark, J. 1993, Extraordinary Encounters: An Encyclopedia of Extraterrestrials and Otherworldly Beings (Detroit: Gale Research)

Cocconi, G. and Morrison, P. 1959, Searching for Interstellar Communications, Nature, 184, 844.

Crews, F. 1986, Project OZMA - how it really was. In The Search for Extraterrestrial Intelligence, ed. K.I. Kellermann and G.A. Seielstad (Green Bank: NRAO/AUI), 27 http://library.nrao.edu/public/collection/02000000000301.pdf

Dick, S.J. 1993, The Search for Extraterrestrial Intelligence and the NASA HRMS: Historical Perspectives, SSRv, 64, 93

Dick, S.J. 1998, Life on Other Worlds: The 20 th Century Extraterrestrial Life Debate (Cambridge: CUP)

Drake, F.D. 1960, How Can We Detect Radio Transmissions from Distant Planetary Systems?, SơT, 19, 140

Drake, F.D. 1961, Project Ozma, PhT, 14, 40

Drake, F.D. 1979, A Reminiscence of Project Ozma, CosSe, 1 (1), 10

Drake, F.D. 1990. In SETI Pioneers: Scientists Talk About Their Search for Extraterrestrial Intelligence, ed. D.S. Swift (Tucson: University of Arizona Press), 54

Drake, F.D. 2010, Astronomy Beat (San Francisco: Astronomical Society of the Pacific)

Drake, F.D. and Sobel, D. 1992, Is Anyone Out There? The Scientific Search for Extraterrestrial Intelligence (New York: Delacorte Press)

Dyson, F. 1971, Letter from Armenia, The New Yorker, November 6, 126

Ekers, R.D. et al. eds. 2002, SETI 2020: A Roadmap for the Search for Extraterrestrial Intelligence (Mountain View, California: SETI Press)

Field, G. ed. 1982, Astronomy and Astrophysics for the 1980s (Washington: National Academy Press)

Garber, S.J. 1999, Searching for Good Science: The Cancellation of NASA's SETI Program, JBIS, 52, 3

Grey, R.H. 2012, The Elusive Wow: Searching for Extraterrestrial Intelligence (Chicago: Palmer Square Press)

Kardashev, N.S. 1964, AZh, 41, 282. English translation: Transmission of Information by Extraterrestrial Civilizations, $S A s, \mathbf{8}, 21$ 
Kellermann, K.I. et al. 1962, A Correlation between the Spectra of Non-thermal Radio Sources and their Brightness Temperatures, Nature, 195, 692

Kellermann, K.I. and Seielstad, G.A. eds. 1986, The Search for Extraterrestrial Intelligence (Green Bank: NRAO/AUI) http://library.nrao.edu/public/collection/02000000000301.pdf

McKee, R. and Taylor, J. eds. 2001, Astronomy and Astrophysics for the New Millennium (Washington: National Academy Press)

Morrison, P. 1990. In SETI Pioneers: Scientists Talk About Their Search for Extraterrestrial Intelligence, ed. D.S. Swift (Tucson: University of Arizona Press), 19

Morrison, P., Billingham, J., and Wolfe, J. eds. 1977, The Search for Extraterrestrial Intelligence, NASA SP-419 (Washington: NASA)

Oliver, B.M. 1979, Rationale for the Water Hole, Acta Astronautica, 6, 71

Oliver, B.M. and Billingham, J. eds. 1973 revised, Project Cyclops: A Design Study for a System for Detecting Extraterrestrial Intelligent Life, NASA CR1 14445 (Originally published 1972, revised 1973, reprinted 1996 by the SETI League and the SETI Institute with additional material)

Palmer, P. and Zuckerman, B. 1972, Ozma Revisited, NRAO Observer, 13 (6), 26 https://science.nrao.edu/about/publications/open-skies\#section-5

Pearman, J.P.T. 1963, Extraterrestrial Intelligent Life and Interstellar Communication: An Informal Discussion. In Interstellar Communication, ed. A.G.W. Cameron (New York: Benjamin), 287

Sagan, C. 1973, The Cosmic Connection: An Extraterrestrial Perspective (Garden City, N.Y.: Anchor Press)

Schorn, R.A. et al. 1968, Quasi-Stellar Radio Sources: 88-GHZ Flux Measurements, ApJ, 151, L27

Scientific Council of the USSR Academy of Sciences 1975, AZh., 51, 112. English translation: The CETI Program, $S v A$, 18, 669

Sholomitsky, G.B. 1965, AZh, 42, 673, English translation: Fluctuations in the 32.5cm Flux of CTA 102, $S v A, 9,516$

Shostak, S. ed. 1993, The Third Decenial US-USSR Conference on SETI (San Francisco: Astronomical Society of the Pacific)

Smith, M. 1975, Possibility of Intelligent Life in the Universe, Report prepared for the Committee on Science and Technology, US House of Representatives, Ninety-Fifth Congress (Washington: Government Printing Office), updated in 1977 to include new astrometric information and the status of the NASA SETI program

Struve, O. 1962, The Universe (Cambridge: MIT Press)

Sullivan, W. 1982, SETI Conference at Tallinn, S\& T, 63, 350

Tarter, J.C. et al. 1980, A High-Sensitivity Search for Extraterrestrial Intelligence at Lambda $18 \mathrm{Cm}$, Icarus, 42, 136

Tarter, J.C. et al. 2010, SETI Turns 50: Five Decades of Progress in the Search for Extraterrestrial Intelligence, Proc. SPIE 7819, Instruments, Methods, and Missions for Astrobiology XIII doi:https://doi.org/10.1117/12.863128

Tovmasyan, G.M., ed. 1964, Extraterrestrial Civilizations(Yerevan: Armenian Academy of Sciences Press) in Russian; English translation for NASA and the NSF from the Israel Program for Scientific Translation, no. 1823 (Springfield, VA: U S. Dept. of Commerce)

Troitsky, V.S. et al. 1971, $A Z h, \mathbf{4 8}, 645$. English translation: Search for Monochromatic 927-MHz Radio Emission from Nearby Stars, $S v A$, 15, 508

Troitsky, V.S. et al. 1974, UsFiN, 13, 718. English translation: The Search for Sporadic Radio Emission from Space, $S v P h U, 17,607,1975$ 
Verschuur, G. 1973, A Search for Narrow Band 21-cm Wavelength Signals from Ten Nearby Stars, Icarus, 19, 329

von Hoerner, S. 1985, Life in Space and Humanity on Earth. In The Search for Extraterrestrial Intelligence, ed. K.I. Kellermann and G.A. Seielstad (Green Bank: NRAO/AUI) http://library.nrao.edu/public/collection/02000000000301.pdf Zuckerman, B. and Tarter, J. 1980, Microwave Searches in the U.S.A. and Canada. In Strategies for the Search for Life in the Universe, ed. M.D. Papagiannis (Dordrecht: Reidel)

\section{FurThER READING}

Bracewell, R. 1974, The Galactic Club: Intelligent Life in Outer Space (San Francisco: W. H. Freeman)

Cameron, A.G.W. ed. 1963, Interstellar Communication (New York: Benjamin)

Davies, P. 2010, The Eerie Silence: Renewing Our Search for Alien Intelligence (Boston: Houghton Mifflin Harcourt)

Dick, S.J. 1996, The Biological Universe: The Twentieth-Century Extraterrestrial Life Debate and the Limits of Science (Cambridge: CUP)

Dick, S.J. 2018, Astrobiology, Discovery, and Societal Impact (Cambridge: CUP)

Isaacson, H. et al. 2017, The Breakthrough Listen Search for Intelligent Life: Target Selection of Nearby Stars and Galaxies, PASP, 129, 054501

Oliver, B.M. 1993, The Search for Extraterrestrial Intelligence, Mercury, 2 (2), 11

Sagan, C. and Drake, F.D. 1975, The Search for Extraterrestrial Intelligence, Scientific American, 232, May, 80

Shklovsky, I.S. and Sagan, C. 1966, Intelligent Life in the Universe (San Francisco: Holden-Day)

SETI@50, Video presentation of talks at workshop held in Green Bank, 13-15 September 2010 on the occasion of the 50th anniversary of Project Ozma, http:// library.nrao.edu/setitoc.shtml

Sullivan, W. 1966, We Are Not Alone (New York: McGraw Hill)

Swift, David S. 1990, SETI Pioneers: Scientists Talk About Their Search for Extraterrestrial Intelligence (Tucson: University of Arizona Press)

Tarter, J. 2001, The Search for Extraterrestrial Intelligence, $A R A A, 39,511$

Vakoch, D.A. and Dowd, M.F. 2015, The Drake Equation: Estimating the Prevalence of Extraterrestrial Life through the Ages (Cambridge: CUP)

Open Access This chapter is licensed under the terms of the Creative Commons Attribution 4.0 International License (http://creativecommons.org/licenses/ by $/ 4.0 /$ ), which permits use, sharing, adaptation, distribution and reproduction in any medium or format, as long as you give appropriate credit to the original author(s) and the source, provide a link to the Creative Commons licence and indicate if changes were made.

The images or other third party material in this chapter are included in the chapter's Creative Commons licence, unless indicated otherwise in a credit line to the material. If material is not included in the chapter's Creative Commons licence and your intended use is not permitted by statutory regulation or exceeds the permitted use, you will need to obtain permission directly from the copyright holder. 